\title{
Bone Micromorphology and Material Attrition After Sonic, Ultrasonic and Conventional Osteotomies
}

\author{
ASHKAN RASHAD ${ }^{1,2}$, STEFAN SCHWAN ${ }^{3}$, ALIREZA NASIRPOUR ${ }^{4}$, INGE SCHMITZ ${ }^{5}$, \\ HENNING HANKEN $^{2}$, REINHARD E. FRIEDRICH ${ }^{2}$ and MARTIN GOSAU ${ }^{2}$ \\ ${ }^{1}$ Department of Oral, Maxillofacial and Facial Plastic Surgery, \\ RWTH Aachen University Hospital, Aachen, Germany; \\ ${ }^{2}$ Department of Oral and Maxillofacial Surgery, University \\ Medical Center Hamburg-Eppendorf, Hamburg, Germany; \\ ${ }^{3}$ Fraunhofer Institute for Microstructure of Materials and Systems (IMWS), Halle (Saale), Germany; \\ ${ }^{4}$ Department of Oral and Maxillofacial Surgery, Tehran University of Medical Sciences, Tehran, Iran; \\ ${ }^{5}$ Department of Pathology, Ruhr University Bochum, Bochum, Germany
}

\begin{abstract}
Background/Aim: Osteotomy as the first step in surgery, provides access to the field and its application could influence the outcome. Nowadays, the conventional burr reduction is being challenged by newer sonic and ultrasonic methods. We investigated the bone structural integrity and metal attrition residues both in bone and the irrigation fluid. Materials and Methods: Bovine ribs were cut using three methods. Bone cuts were studied using Environmental Scanning Electron Microscopy (ESEM) for tissue discrepancies and Scanning Electron Microscopy/Energy Dispersion X-Ray Microanalysis (SEM/EDX) for organic and inorganic debris. Results: Better preservation of bone architecture was seen in piezo and sono surgery while metal attrition was not conclusive $(p>0.05)$. Unlike in bone analyses, both bur and ultrasonic osteotomies showed statistically significant higher median inorganic detection per analysis $(p=0.021$ and $p=0.037$, respectively). Conclusion: Sono and piezo surgery proved to be less invasive while attrition properties were the same.
\end{abstract}

Bone reduction is the first stage of many procedures in various fields of medicine, aiming at reshaping the bone, allowing access to the underlying structures or making space for a

This article is freely accessible online.

Correspondence to: Reinhard E. Friedrich, MD, DMD, Ph.D., FEBOMFS, Department of Oral and Craniomaxillofacial Surgery, Eppendorf University Hospital, University of Hamburg, Martinist. 52, D-20246 Hamburg, Germany. Tel: +49 40741053259, e-mail: rfriedrich@uke.de

Key Words: Piezo surgery, sono surgery, conventional surgery, osteotomy, micromorphology, material attrition. substituting implant. Either way this can inviolably influence the fate of the operation by violation of the surgical site, and thus reduce healing quality and velocity or interfere in the osseointegration of the implanted material by jeopardizing the cicatrization by fibrous tissue. Therefore, it is of paramount importance to undertake this step with minimal damage to the bone structure and preserve its viability.

Bone reduction has evolved from use of chisel and hammer to the latest of innovations emerged by the use of electricity (1). Procuring high precision, minimally invasive surgical methods gained in importance. Recently, the introduction of high frequency wave empowered instruments has revolutionized this scheme. Piezo surgery, first introduced in 1988, is based on ultrasonic microvibrations, ranging from 24 to $36 \mathrm{kHz}$ and an amplitude varying from 20 to $200 \mu \mathrm{m}$. This method is believed to procure a more precise cut, producing meticulous and controllable surgical action (2). Its selective functionality on the mineralized tissue, which leads to bone reduction without invading the soft tissue integrity (3) and better post-op healing results compared with rotary instruments, were assessed by various experimental animal studies (4). Since it was first commercialized in 2002, piezo surgery has been employed for different surgical approaches in oral surgery such as maxillary sinus augmentation, ridge expansion, bone block harvesting, tooth extraction, implant site preparation as well as in other fields of medicine, namely, maxillofacial surgery, otorhinolaryngology, orthopedics and neurosurgery (4-8). As a more recent advancement, sonic instruments benefit from a compressed-air-powered tip, making it possible to connect it to the dental unit, capable of vibrations around $6 \mathrm{kHz}$ and wavelength of $240 \mu \mathrm{m}$ which could perform osteotomy. In opposition to the linear motion of the ultrasonic instruments, sonic tips rotate with a circular tapping motion and being 
active on all sides, could cut bone in all directions without need to change the tip orientation $(9,10)$.

Any contamination during the surgery could potentially compromise osseointegration and wound healing, including metal attrition, presumably mostly derived from the osteotomy procedure. This could initiate hypersensitivity and inflammatory reactions at the surgical site, hindering or complicating the healing and the ultimate osseointegration phenomenon. Osteotomy tip remnants are of biomaterial and non-biomaterial origin. The body of literature on the osteotomy-instrumentdriven metal attrition is extremely limited and studies are mainly focused on implant-derived contaminants. As mentioned, the non-invasiveness, or more realistically put, lessinvasiveness, of the osteotomy method is among the sought goals of the osteotomy technique and this could be also attributed to the preservation of the bone structure at the microscopic level. Cancellous bone, being the fundamental blood supply and therefore, responsible for the healing process, could perform its role the most, or at least is so supposed, when it is least disrupted and condensed with debris. So a method that preserves the bone's microstructure could be more preferred $(11,12)$. This study aimed to investigate bone surface integrity and instrument-driven metal attrition while osteotomy with different conventional, piezoelectric and sono surgery devices.

\section{Materials and Methods}

Osteotomy systems and tips. The KaVo INTRAsurg 1000 (13) was used as conventional system with a Lindemann bur H254E (KOMET/GEBR. BRASSELER GmbH \& Co. KG, Lemgo, Germany). While the ultrasonic system comprised a piezo surgery device with an ultrasonic tip OT7S-4 (MECTRON MEDICAL TECHNOLOGY, Carasco, Italy), the sonic system comprised a KaVo INTRAsurg 1000 Air (KAVO DENTAL GmbH) with a SF1LM handpiece and a sonic tip SFS 101 (KOMET/GEBR. BRASSELER GmbH \& Co. KG). The applied tips are shown in Figure 1 (after performed osteotomy).

Bone. Osteotomies were performed on a $30 \mathrm{~mm}$ straight marked line on fresh bovine ribs that were tempered at $20 \pm 0.5^{\circ} \mathrm{C}$ by water quenching. Bovine ribs were provided by a local slaughterhouse and represent a well established bone model for the human mandible due to similarities in bone density and the ratio between cortical and cancellous bone $(13,14)$.

Environmental scanning electron microscopy (ESEM). Two randomly selected samples from each system were submitted for ESEM (FEI/XL 30 ESEM-FEG, PHILIPS, Eindhoven, Netherlands). It is worth mentioning that in fact, more than 2 samples were examined. The results of 2 randomly selected samples from two preparations were exemplary presented. This is divided into 2 bone samples and 2 filtration product samples, which were analyzed 40 or 45 times for each osteotomy method, respectively. Presentation was performed similarly to a study by Amadasi et al. (14) on the metallic residues from gunshot wounds in cremated bone hiring SEM/EDX. A gaseous secondary electron (GSE) detector, which was operated at an acceleration voltage of $10 \mathrm{kV}$,
6.5-8 mm sample-detector distance, 4.0 spot size, and $186.65 \mathrm{Nm} 2$ was used to view the sample surface morphology. Images of the cut surfaces were taken at $200 \times$ magnification as an overview (15).

Scanning electron microscopy/energy dispersion X-ray microanalysis (SEM/EDX). Two randomly chosen preparations from the bur group and two from each of the ultrasonic and sonic groups were submitted to SEM/EDX to detect possible drill deposits in bone. The bone samples were dehydrated with alcohol (30\% to $100 \%$ ethanol), critical point dried, and gold sputtered (15).

It was $25 \mathrm{kV}$ with measurements made at $15 \mathrm{~mm}$ working distance. Semiquantitative assessments were performed. Point analyzes were carried out and partially executed mappings. $\mathrm{KeV}$ interval was 0-5. Calibration was carried out using $\mathrm{Cu}$ standard with ZAF correction performed. Irrigation liquid throughout the implant site preparation by either bur, ultrasonic, or sonic drillings were collected in glass containers and filtered via $\mathrm{N}$ track-etched polycarbonate membranes (WHATMAN, Kent, UK) with a defined pore size of $0.4 \mu \mathrm{m}$. The membranes were sputtered on both sides with a 20-nm gold layer and submitted to SEM/EDX to detect possible washed attrition (15). Non-conductive samples were sputter coated. Bone samples were dried at critical point and treated with a $40 \mathrm{~nm}$ carbon layer. This is not performed for conductive samples like drilling tips. At study time, it was conventional SEM with a tungsten cathode. Measurements were made at $15 \mathrm{~mm}$ working distance, since EDX was calibrated to this. Dead time for the spectra was below $10 \%$. Point analyzes were carried out and partially executed mappings.

Statistics for EDX. The EDX statistics used was the same as our previous report. The frequency of detection of each element (Detection Frequency: DF) relative to the total number of analyses (Analysis Time: AT) was calculated and described as Detection Rate ( $\mathrm{DR}=\mathrm{DF} / \mathrm{AT})$ in percentage. $\mathrm{DR}$ of each element was compared to that of the other groups using pairwise Fisher's exact test.

The elements were classified into those expected to be of normal tissue origin or assumed to be easily integrated into the normal tissues (organic) and those not expected to be of normal tissue origin (inorganic). The sum of DFs of the organic elements (DFo) and that of the inorganic elements (DFi) were calculated. The Inorganic Proportion (8) of each system was then calculated as the DFi divided by the total DF of all the elements in each group $\left(\mathrm{IP}=\mathrm{DF}_{\mathrm{i}} / \mathrm{DF}_{\mathrm{o}}+\mathrm{DF}_{\mathrm{i}}\right)$ in percentage. IP of the three systems was compared using pairwise Fisher's exact test.

For further accuracy (eliminating the possible biasing effect of $\mathrm{D}_{\mathrm{FO}}$ in the calculation of IP), the median number of inorganic detections per analysis was calculated and the three study groups were compared regarding these data using pairwise Fisher's exact test (15). Gold $(\mathrm{Au})$ was always considered to be from the preparation and was excluded from all measurements. Bonferroni correction was used in all statistical analysis.

\section{Results}

ESEM. Typical cortical and cancellous structures of bovine rib were detected by all three systems. However, bur osteotomy resulted in smeared cancellous chambers and the anatomical structure was not retained. Sonic osteotomies resulted in chambers nearly free of debris and intact 


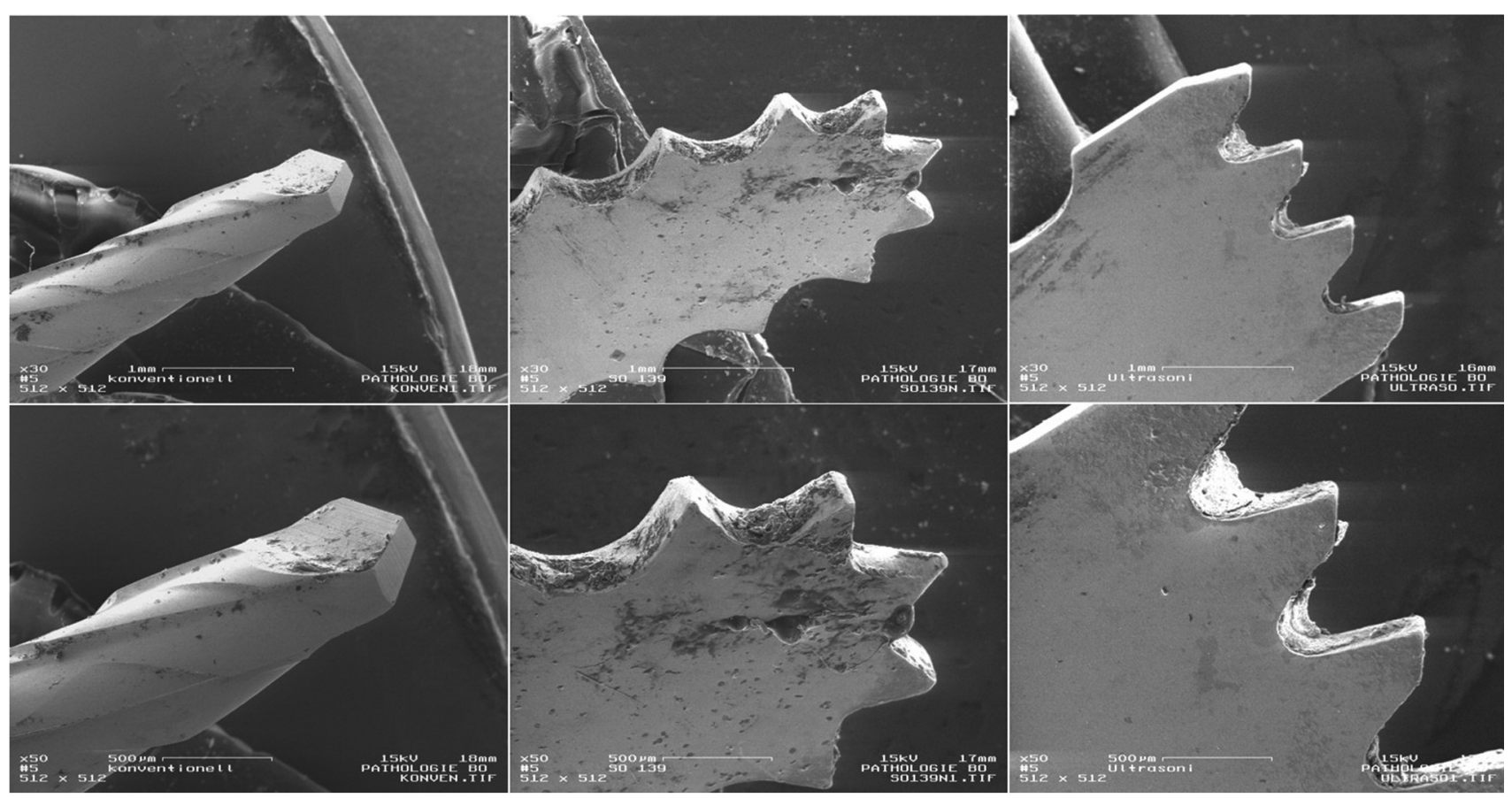

Figure 1. Scanning electron microscope (SEM) imaging of the three different applied tips (from left to right: Lindemann bur H254E, sonic saw SFS 101 and ultrasonic saw OT7S-4) at 30x magnification (upper row) and 50x magnifications (lower row).

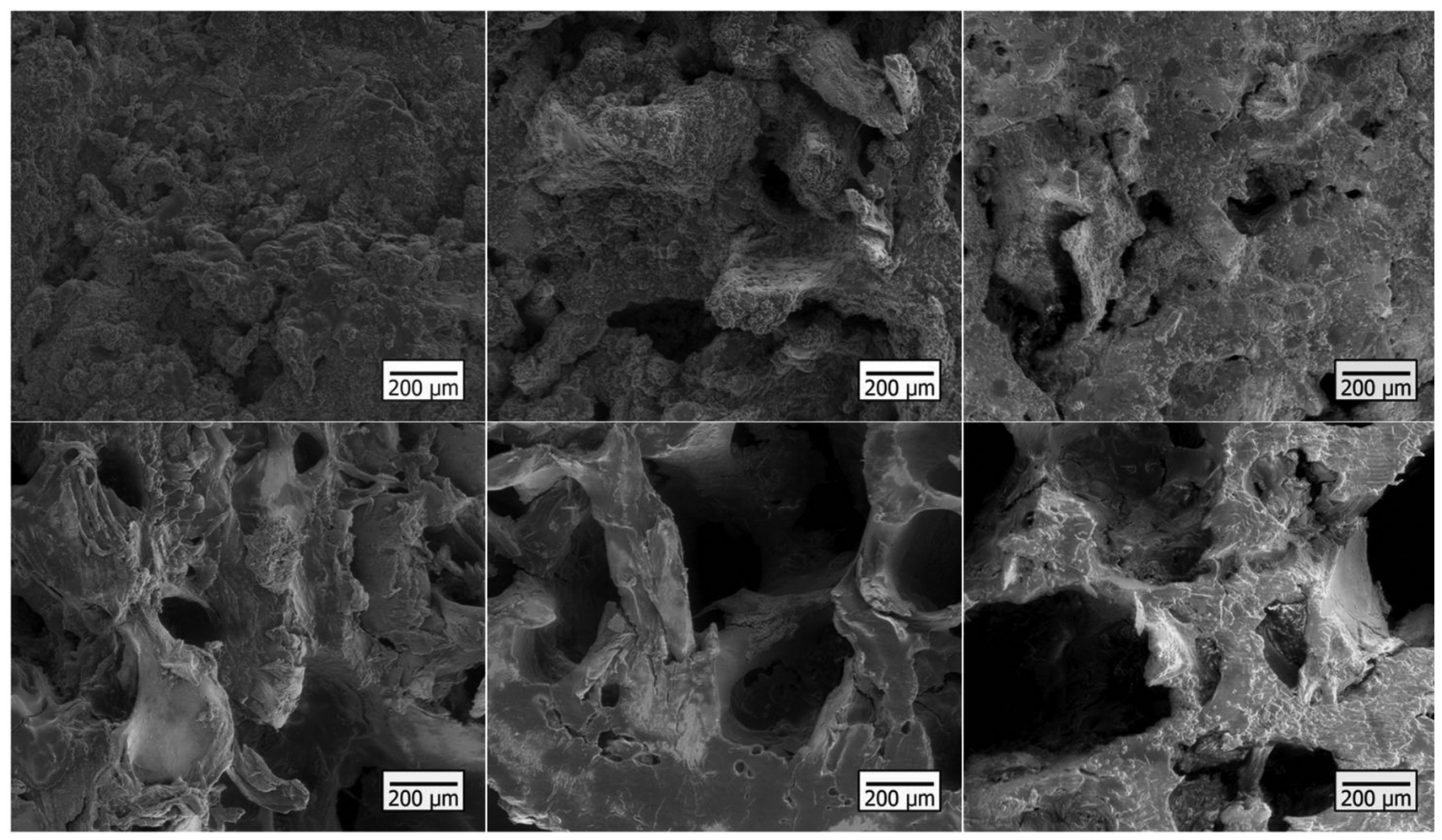

Figure 2. Environmental scanning electron microscopy (ESEM) of the cortico-cancellous junction of the studied bone after conventional, sonic and piezo osteotomy (from left to right) with (lower row) and without (upper row) irrigation. 


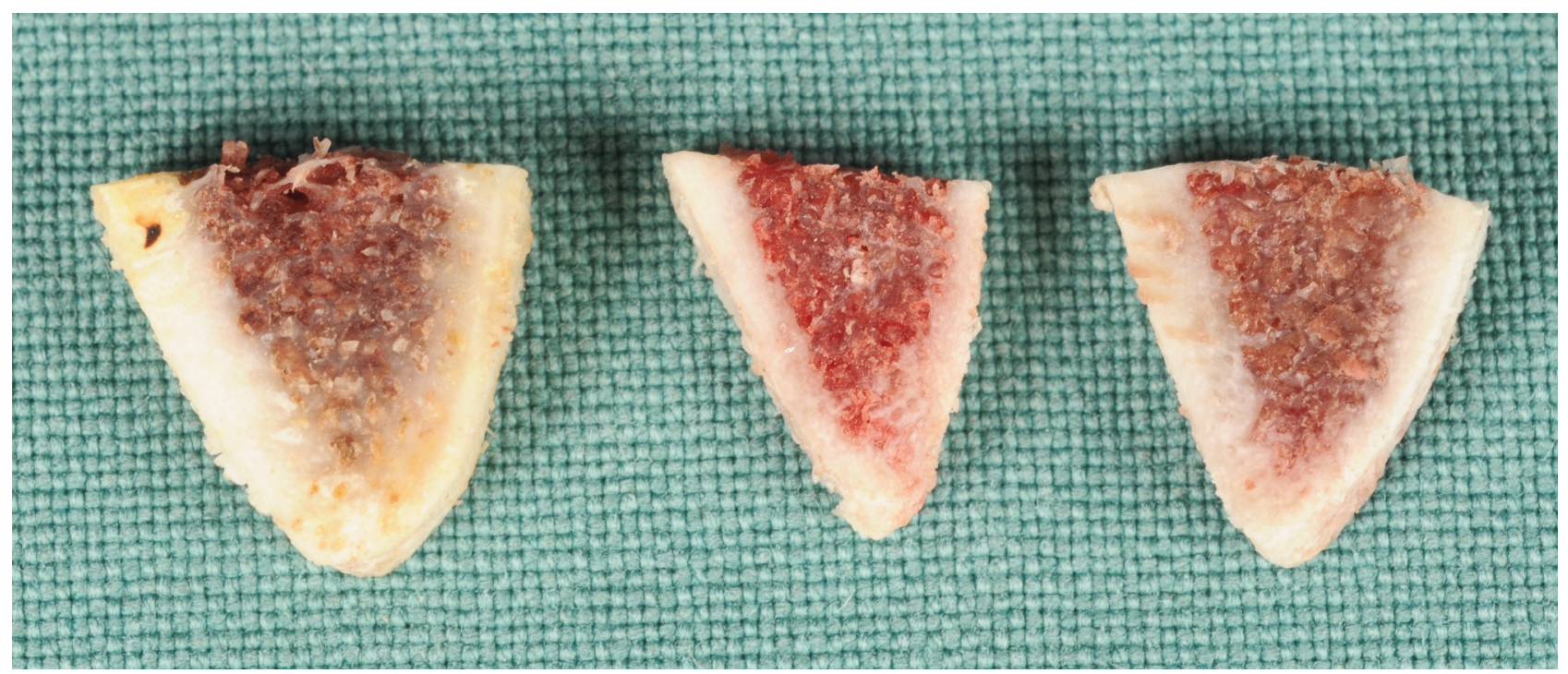

Figure 3. Macroscopical illustration of the studied bone after conventional, sonic and piezo osteotomy (from left to right) without any irrigation. General inspection of the samples shows some brown, burning-like color alternation in the conventional method while the sono and ultrasonic samples maintain a natural pink color on the cutting surface.

trabeculae. Same bone structure preservation was observed using ultrasonic osteotomy but with more debris and surface irregularities. These impressions intensified with use of no irrigation volume (Figure 2). Even macroscopically, the exceptional osteotomy without any irrigation suggested similar impressions (Figure 3).

SEM/EDX - Bone. Si, Mg, Ti, and $\mathrm{Al}$ in descending order of DF, were detected (Table I). Pairwise exact Fisher's test showed no statistically significant difference between the DF of each of these elements between the three study groups. The detected gold was from the gold sputter while specimen preparation. Also, pairwise exact Fisher's test did not show any statistically significant difference in the IP of the three studied systems compared two by two. Moreover, no statistically significant difference was found between the three study groups in terms of median inorganic element detection per analysis (Tables II and III).

SEM/EDX - Irrigation. $\mathrm{Mg}$ and $\mathrm{Si}$ in descending DF order were detected. Single detections of $\mathrm{Zr}, \mathrm{Mn}, \mathrm{Ti}, \mathrm{Mo}$, As, and $\mathrm{Cu}$ were also detected (Table IV). Pairwise exact Fisher's test showed no statistically significant difference between the DF of each of these elements between the three study groups. The detected gold was from the gold sputter while specimen preparation. Unlike in the bone analyses, both bur and ultrasonic osteotomies showed statistically significant higher median inorganic detection per analysis $(p=0.021$ and 0.037 , respectively) (Tables II and V).

\section{Discussion}

In this in vitro study, micro morphological integrity of the bone and the metal attrition, both deposited in the bone and the irrigation liquid, was assessed. In terms of preservation of bone microstructure, the ESEM of the bone surface revealed superior results in sonic surgery compared to piezo and conventional Lindemann bur, respectively. The margins dividing the cortical and cancellous regions were most and least intact in the sono surgery and conventional samples, respectively, which is in accordance with the previous studies $(15,16)$. Besides, debris accumulated in the trabecular spaces was reported to be less in sono surgery than in piezo and conventional osteotomy. In an orderly manner, this was most likely attributed to the cavitational effect of the sono and piezo, detaching the particles by their vibration, and also to the amount of irrigation used during osteotomy with these instruments. The cavitational effect is also suggested to lead to less bacterial contamination by dismantling the bacteria's cellular membrane (17). Another reason associated with the cleaner cutting surface of sono and piezo surgery could be regarded as the sheer amount of operation time in these methods which is reportedly more than the conventional method (18-21). This is presumed to contribute to a superior healing and osseointegration as the blood flow disruption in minimal and also the less damage to the bone structure would simply bear less inflammatory reactions and fibrous tissue formation (22). The statistical analysis of the debris accumulation in bone showed 
Table I. Detection frequency of organic (upper row) and inorganic (lower row) elements found by Scanning Electron Microscopy/Energy Dispersion $X$-Ray Microanalysis on the bone cut with the three studied osteotomy systems. Values in parentheses are in \% of the total analyses times (45 for conventional and sonosurgery; 40 for piezosurgery) for each system.

\begin{tabular}{lcccccc}
\hline & $\mathrm{C}$ & $\mathrm{O}$ & $\mathrm{P}$ & $\mathrm{Ca}$ & $\mathrm{Na}$ & $\mathrm{N}$ \\
\hline Conventional & $30(66.7)$ & $44(97.8)$ & $45(100)$ & $45(100)$ & $23(51.1)$ & $15(33.3)$ \\
Piezosurgery & $37(92.5)$ & $35(87.5)$ & $34(85)$ & $38(95)$ & $11(27.5)$ & $1(2.5)$ \\
Sonosurgery & $45(100)$ & $43(95.6)$ & $44(97.8)$ & $44(97.8)$ & - & - \\
\hline & $\mathrm{Al}$ & $\mathrm{Si}$ & $\mathrm{Ti}$ & $\mathrm{Mg}$ & & - \\
\hline Conventional & $2(4.4)$ & $6(13.3)$ & $1(2.2)$ & - & \\
Piezosurgery & - & $1(2.5)$ & $1(2.5)$ & $3(7.5)$ & & \\
Sonosurgery & - & $7(15.6)$ & $2(4.4)$ & $3(6.7)$ & & \\
\hline
\end{tabular}

Table II. Detection frequency of organic (DFo) and inorganic (DFi) elements with calculated inorganic portion (IP) for both bone and irrigation volume among 3 studied systems.

\begin{tabular}{|c|c|c|c|c|c|c|}
\hline & \multicolumn{3}{|c|}{ Bone } & \multicolumn{3}{|c|}{ Irrigation } \\
\hline & $\mathrm{DF}_{\mathrm{o}}$ & $\mathrm{DF}_{\mathrm{i}}$ & IP & $\mathrm{DF}_{\mathrm{o}}$ & $\mathrm{DF}_{\mathrm{i}}$ & IP \\
\hline Conventional & 202 & 9 & $9 / 211=4.3 \%$ & 176 & 12 & $12 / 188=6.4 \%$ \\
\hline Piezosurgery & 157 & 5 & $5 / 162=3.1 \%$ & 183 & 11 & $11 / 194=5.7 \%$ \\
\hline Sonosurgery & 176 & 12 & $12 / 188=6.4 \%$ & 168 & 8 & $8 / 176=4.5 \%$ \\
\hline
\end{tabular}

Table III. Median element detection analysis for organic and inorganic elements in bone and belonging p-values between 3 studied systems.

\begin{tabular}{lcr}
\hline & Organic elements & Piezosurgery $v s$. Sonosurgery \\
\hline Conventional $v s$. Piezosurgery & Conventional $v s$. Sonosurgery & 0.213 \\
\hline 0.596 & 0.376 & Piezosurgery vs. Sonosurgery \\
\hline Conventional $v s$. Piezosurgery & Conventional $v s$. Sonosurgery & 1.000 \\
\hline 0.772 & 0.550 &
\end{tabular}

significant difference in neither study groups for both organic and inorganic substances. The inorganic irrigation fluid attrition volume bear significant difference between conventional and sonic and also between piezo and sonic with the sonic leading to lesser quantitative results. This result could not be interpreted necessarily as the inferiority of the one method compared to the other, since the sheer amount of the produced debris was not studied, but the main focus was on the comparative relations of the accumulated debris in the bone and the irrigation fluid. Paying attention solely on the greater deposited debris in the irrigation fluid may not direct us to a comprehensive conclusion. Metal attrition ion remnants in the bone could bear various adverse effects, compromising optimal surgical results. Debris of Ni have been found to lead to morphological alterations and calling several inflammatory cascades that could harm and jeopardize osseointegration, even without significantly detectable metallosis (23). In a study by Esposito et al. it was 
in vivo $35: 1499-1506(2021)$

Table IV. Detection Frequency of organic (upper row) and inorganic (lower row) elements found by scanning electron microscopy/energy dispersion $X$-Ray microanalysis within filtered irrigation liquid of the three studied osteotomy systems. Values in parentheses are in $\%$ of the total analyses times (45) for each system.

\begin{tabular}{lccccccc}
\hline & $\mathrm{C}$ & $\mathrm{O}$ & $\mathrm{P}$ & $\mathrm{Ca}$ & $\mathrm{N}$ & $\mathrm{S}$ & $\mathrm{Na}$ \\
\hline Conventional & $44(97.8)$ & $40(88.9)$ & $44(97.8)$ & $45(100)$ & - & - & $3(6.7)$ \\
Piezosurgery & $45(100)$ & $43(95.6)$ & $45(100)$ & $45(100)$ & - & - & $5(11.1)$ \\
Sonosurgery & $44(97.8)$ & $43(95.6)$ & $37(82.2)$ & $40(88.9)$ & $1(2.2)$ & $1(2.2)$ & $2(4.4)$ \\
\hline & $\mathrm{Mg}$ & $\mathrm{Zr}$ & $\mathrm{Mn}$ & $\mathrm{Ti}$ & $\mathrm{Si}$ & $\mathrm{Mo}$ & $\mathrm{As}$ \\
\hline Conventional & $8(17.8)$ & - & $1(2.2)$ & $1(2.2)$ & - & - & $1(2.2)$ \\
Piezosurgery & $9(20.0)$ & - & - & - & $1(2.2)$ & $1(2.2)$ & - \\
Sonosurgery & $6(13.3)$ & $1(2.2)$ & - & - & $1(2.2)$ & - & - \\
\hline
\end{tabular}

Table V. Median element detection analysis for organic and inorganic elements for irrigation volume and belonging p-values between the three studied systems.

\begin{tabular}{lcr}
\hline & Organic elements & Piezosurgery $v s$. Sonosurgery \\
\hline Conventional $v s$. Piezosurgery & Conventional $v s$. Sonosurgery & 0.647 \\
\hline 0.832 & 0.496 & Piezosurgery vs. Sonosurgery \\
\hline Conventional $v s$. Piezosurgery & Conventional $v s$. Sonosurgery & 0.037 \\
\hline 1.000 & 0.021 & \\
\hline
\end{tabular}

shown that the Si contamination of implants came from the ion leaching of the glass vials in which the implant is restored. The same study suggested that the $\mathrm{Mg}$ contamination could be derived from the powder of surgical gloves (24). Whereas the organic residues from the drilling might induce osteoclastogenesis before osteogenesis the physical obstruction of the trabeculae and reduced blood flow is a threat for healing process and thus the osseointegration $(25,26)$. One rather ambitious hypothesis is that the produced debris is retained inside the bone and has not been teetered into the irrigation fluid. However, this would be in contrast to what has been proposed about the role of the cavitational effect on higher cleansing of the bone. In addition, the fact that the present debris in the bone was statistically insignificantly different between the study groups, suggesting that the utter amount of attrition was not that incoherent, acts as a support to this hypothesis. It is also worth mentioning that the sets of drills used in the present study were new for each sample. The leached elements could be attributed to the newness of the drills. Furthermore, micro-morphological results in this study were achieved in quite occasional circumstances that the drills were being used for the first time and used sets of drills may result in incalculably less favorable outcome. Figure 2 shows less destruction of macro morphology of bone and preservation of osseous architecture especially for sono-driven osteotomy. Even though this result was obtained in the unlikely event of osteotomy without irrigation, the examination revealed less invasive properties of vibration-powered methods. Hitherto, there is sufficient scientific background for the superiority of the sonic and ultrasonic methods compared to the conventional techniques in the field of osteotomy. This advantage becomes even more obvious in cases of proximity of instruments with delicate structures such as maxillary sinus or mandibular nerve repositioning. In an attempt to arrive to a clinically supported verdict about the three methods, Pavlíková et al. failed to conclude due to the lack of, at the time, clinical data and acquiesced to the statement that different indications for each method must be prioritized at the time of treatment planning (27). Chiriac et al. 
suggested that the cell viability and differentiation capability is comparably sustained based on the bone graft harvested in normal surgical procedures (28). It should be mentioned that the SEM used in this study was the DSM 940 (CARL ZEISS AG, Oberkochen, Germany) whose detector does not provide backscatter mode which improves small particle detection in a rather time consuming yet more feasible fashion. More advanced equipment could potentially lead to more in depth studies and are recommendable for future research agenda.

\section{Conclusion}

In this study, both piezo and sono surgery showed less invasive osteotomy properties with all three studied systems indicating similar attrition attributes while underlining effectiveness of performed irrigation.

\section{Conflicts of Interest}

The Authors have no conflicts of interest with regard to the work presented. This research did not receive any specific grant from funding agencies in the public, commercial, or not-for-profit sectors.

\section{Authors' Contributions}

All Authors contributed to the design of the study, evaluation of data, and writing of the manuscript. All Authors have released the manuscript for publication.

\section{References}

1 Dabis J, Templeton-Ward O, Lacey AE, Narayan B and Trompeter A: The history, evolution and basic science of osteotomy techniques. Strategies Trauma Limb Reconstr 12(3): 169-180, 2017. PMID: 28986774. DOI: 10.1007/s11751-0170296-4

2 Vercellotti T: Technological characteristics and clinical indications of piezoelectric bone surgery. Minerva Stomatol 53(5): 207-214, 2004. PMID: 15263877.

3 Schaeren S, Jaquiéry C, Heberer M, Tolnay M, Vercellotti T and Martin I: Assessment of nerve damage using a novel ultrasonic device for bone cutting. J Oral Maxillofac Surg 66(3): 593-596, 2008. PMID: 18280402. DOI: 10.1016/j.joms.2007.03.025

4 Preti G, Martinasso G, Peirone B, Navone R, Manzella C, Muzio G, Russo C, Canuto RA and Schierano G: Cytokines and growth factors involved in the osseointegration of oral titanium implants positioned using piezoelectric bone surgery versus a drill technique: A pilot study in minipigs. J Periodontol 78(4): 716722, 2007. PMID: 17397320. DOI: 10.1902/jop.2007.060285

5 Anitua E, Begoña L and Orive G: Clinical evaluation of splitcrest technique with ultrasonic bone surgery for narrow ridge expansion: Status of soft and hard tissues and implant success. Clin Implant Dent Relat Res 15(2): 176-187, 2013. PMID: 21453394. DOI: 10.1111/j.1708-8208.2011.00340.x

6 Rullo R, Addabbo F, Papaccio G, D'Aquino R and Festa VM: Piezoelectric device vs. conventional rotative instruments in impacted third molar surgery: Relationships between surgical difficulty and postoperative pain with histological evaluations. J Craniomaxillofac Surg 41(2): e33-e38, 2013. PMID: 22890087. DOI: $10.1016 / j . j c m s .2012 .07 .007$

7 Stacchi C, Vercellotti T, Torelli L, Furlan F and Di Lenarda R: Changes in implant stability using different site preparation techniques: Twist drills versus piezosurgery. A single-blinded, randomized, controlled clinical trial. Clin Implant Dent Relat Res 15(2): 188-197, 2013. PMID: 21682844. DOI: 10.1111/ j.1708-8208.2011.00341.x

8 Stuibinger S, Kuttenberger J, Filippi A, Sader R and Zeilhofer HF: Intraoral piezosurgery: Preliminary results of a new technique. J Oral Maxillofac Surg 63(9): 1283-1287, 2005. PMID: 16122591. DOI: 10.1016/j.joms.2005.05.304

9 Agabiti I: Split crest con strumenti vibranti a bassa frequenza: Un caso clinico. Dental Cadmos 79(9): 645-656, 2020. DOI: 10.1016/j.cadmos.2011.05.005

10 Papadimitriou DE, Geminiani A, Zahavi T and Ercoli C: Sonosurgery for atraumatic tooth extraction: a clinical report. J Prosthet Dent 108(6): 339-343, 2012. PMID: 23217465. DOI: 10.1016/S0022-3913(12)00169-2

11 Maurer P, Kriwalsky MS, Block Veras R, Vogel J, Syrowatka F and Heiss C: Micromorphometrical analysis of conventional osteotomy techniques and ultrasonic osteotomy at the rabbit skull. Clin Oral Implants Res 19(6): 570-575, 2008. PMID: 18474063. DOI: 10.1111/j.1600-0501.2007.01516.x

12 Schweiberer L, Dambe LT, Eitel F and Klapp F: Revascularization of the tibia after conservative and surgical fracture fixation. Hefte Unfallheilkd (119): 18-26, 1974. PMID: 4459360.

13 Gehrke SA, Aramburú Júnior JS, Pérez-Albacete Martínez C, Ramirez Fernandez MP, Maté Sánchez de Val JE and CalvoGuirado JL: The influence of drill length and irrigation system on heat production during osteotomy preparation for dental implants: An ex vivo study. Clin Oral Implants Res 29(7): 772778, 2018. PMID: 27041138. DOI: 10.1111/clr.12827

14 Amadasi A, Brandone A, Rizzi A, Mazzarelli D and Cattaneo C: The survival of metallic residues from gunshot wounds in cremated bone: A SEM-EDX study. Int J Legal Med 126(4): 525531, 2012. PMID: 22249273. DOI: 10.1007/s00414-011-0661-7

15 Rashad A, Sadr-Eshkevari P, Weuster M, Schmitz I, Prochnow $\mathrm{N}$ and Maurer P: Material attrition and bone micromorphology after conventional and ultrasonic implant site preparation. Clin Oral Implants Res 24(Suppl A100): 110-114, 2013. PMID: 22248387. DOI: 10.1111/j.1600-0501.2011.02389.x

16 Simonetti M, Facco G, Barberis F, Signorini G, Capurro M, Rebaudi A and Sammartino G: Bone characteristics following osteotomy surgery: An in vitro sem study comparing traditional lindemann drill with sonic and ultrasonic instruments. Poseido 1: 187-194, 2013.

17 Arrojo S, Benito Y and Tarifa AM: A parametrical study of disinfection with hydrodynamic cavitation. Ultrason Sonochem 15(5): 903-908, 2008. PMID: 18077202. DOI: 10.1016/ j.ultsonch.2007.11.001

18 Gruber RM, Kramer FJ, Merten HA and Schliephake H: Ultrasonic surgery - an alternative way in orthognathic surgery of the mandible. A pilot study. Int J Oral Maxillofac Surg 34(6): 590-593, 2005. PMID: 16053884. DOI: 10.1016/j.ijom.2005. 06.006

19 Rashad A, Kaiser A, Prochnow N, Schmitz I, Hoffmann E and Maurer P: Heat production during different ultrasonic and conventional osteotomy preparations for dental implants. Clin 
Oral Implants Res 22(12): 1361-1365, 2011. PMID: 21435005. DOI: $10.1111 / \mathrm{j} .1600-0501.2010 .02126 . x$

20 Rashad A, Sadr-Eshkevari P, Heiland M, Smeets R, Prochnow N, Hoffmann E and Maurer P: Practitioner experience with sonic osteotomy compared to bur and ultrasonic saw: A pilot in vitro study. Int J Oral Maxillofac Surg 44(2): 203-208, 2015. PMID: 25277806. DOI: 10.1016/j.ijom.2014.09.004

21 Robiony M, Polini F, Costa F, Vercellotti T and Politi M: Piezoelectric bone cutting in multipiece maxillary osteotomies J Oral Maxillofac Surg 62(6): 759-761, 2004. PMID: 15170295. DOI: $10.1016 /$ j.joms.2004.01.010

22 Stacchi C, Berton F, Turco G, Franco M, Navarra CO, Andolsek F, Maglione M and Di Lenarda R: Micromorphometric analysis of bone blocks harvested with eight different ultrasonic and sonic devices for osseous surgery. J Craniomaxillofac Surg 44(9): 1143-1151, 2016. PMID: 27527676. DOI: 10.1016/ j.jcms.2016.04.024

23 Parvizi J, Suh DH, Jafari SM, Mullan A and Purtill JJ: Aseptic loosening of total hip arthroplasty: Infection always should be ruled out. Clin Orthop Relat Res 469(5): 1401-1405, 2011. PMID: 21365337. DOI: 10.1007/s11999-011-1822-1

24 Esposito M, Lausmaa J, Hirsch JM and Thomsen P: Surface analysis of failed oral titanium implants. J Biomed Mater Res 48(4): 559-568, 1999. PMID: 10421701. DOI: 10.1002/(sici) 1097-4636(1999)48:4<559::aid-jbm23>3.0.co;2-m
25 Yeniyol S, Jimbo R, Marin C, Tovar N, Janal MN and Coelho PG: The effect of drilling speed on early bone healing to oral implants. Oral Surg Oral Med Oral Pathol Oral Radiol 116(5): 550-555, 2013. PMID: 24055149. DOI: 10.1016/j.oooo.2013.07.001

26 Lahens B, Neiva R, Tovar N, Alifarag AM, Jimbo R, Bonfante EA, Bowers MM, Cuppini M, Freitas H, Witek L and Coelho PG: Biomechanical and histologic basis of osseodensification drilling for endosteal implant placement in low density bone. An experimental study in sheep. J Mech Behav Biomed Mater 63: 5665, 2016. PMID: 27341291. DOI: 10.1016/j.jmbbm.2016.06.007

27 Pavlíková G, Foltán R, Horká M, Hanzelka T, Borunská H and Sedý J: Piezosurgery in oral and maxillofacial surgery. Int J Oral Maxillofac Surg 40(5): 451-457, 2011. PMID: 21176870. DOI: 10.1016/j.ijom.2010.11.013

28 Chiriac G, Herten M, Schwarz F, Rothamel D and Becker J: Autogenous bone chips: Influence of a new piezoelectric device (Piezosurgery) on chip morphology, cell viability and differentiation. J Clin Periodontol 32(9): 994-999, 2005. PMID: 16104964. DOI: 10.1111/j.1600-051X.2005.00809.x

Received February 25, 2021

Revised March 17, 2021

Accepted March 31, 2021 